\title{
Extremely Rare Primary Spinal Epidural Indolent Mantle Cell Lymphoma: A Case Report With Literature Review
}

\author{
Rohit Prasad ${ }^{1}$, Nishan B. Pokhrel ${ }^{1}$, Sushil Paudel ${ }^{1}$, Dinesh Kafle ${ }^{1}$, Rohit K. Pokharel ${ }^{1}$ \\ 1. Orthopaedics, Tribhuvan University Institute of Medicine, Kathmandu, NPL
}

Corresponding author: Rohit K. Pokharel, pokharel.rohit@gmail.com

\begin{abstract}
Lymphomas are malignant tumors arising from lymphoid tissues and can spread to other organs. Primary extra-nodal locations such as the spinal epidural space are less common. Primary spinal epidural lymphoma (PSEL), which can be either Hodgkin's or non-Hodgkin's type, is rare. There are different cell types of NonHodgkin's PSEL, among which mantle cell lymphoma (MCL) is extremely rare. MCL can have an aggressive or indolent course. Indolent MCL in the epidural space is not yet reported. We report a case of 20-year-old male who presented with radiating low back pain for six weeks followed by a progressive neurological deficit in both lower limbs for nine days. Magnetic resonance imaging (MRI) revealed spinal epidural tumor extending from L2 to L3. Decompression and subtotal excision biopsy were performed. Histopathology and immunohistochemistry identified indolent MCL. His neurological status improved to normal postoperatively, and he was referred to an oncologist. He is under observation and planned for radiotherapy. At one-year follow-up, he is asymptomatic and doing his regular job abroad.
\end{abstract}

Categories: Neurosurgery, Orthopedics, Hematology

Keywords: indolent, mantle cell, non-hodgkin's lymphoma, primary spinal epidural lymphoma

\section{Introduction}

Lymphoma, a neoplastic disorder of lymphoid tissue, can involve the vertebral body, epidural compartment, spinal cord, and cauda equina [1]. Primary epidural location of lymphomas, both Hodgkin's and nonHodgkin's, is very rare due to which the diagnosis is challenging. Non-Hodgkin's lymphoma (NHL) compromises different cellular types of lymphomas. Mantle cell lymphoma (MCL) is a mature B-cell NHL [2]. It is characterized by monotonous proliferation of atypical small lymphoid cells growing in mantle zone, nodular, or diffuse patterns [3]. Chromosomal translocation $\mathrm{t}(11: 14)$ that leads to cell cycle dysregulation is the molecular hallmark [4]. The clinical course of MCL may be aggressive or slow-growing (indolent), which is determined by over- or under-expression of genes such as SOXII and TP53 [5,6]. Mantle Cell Lymphoma International Prognostic Index (MIPI), together with Ki67 protein level, can predict the prognosis of MCL [7].

Review began 03/11/2021 Review ended 04/26/2021 Published 04/29/2021

\section{○ Copyright 2021}

Prasad et al. This is an open access article distributed under the terms of the Creative Commons Attribution License CC-BY 4.0., which permits unrestricted use, distribution, and reproduction in any medium, provided the original author and source are credited.
Primary MCL in the spine and epidural space is extremely rare. To date, there are only three reported cases of primary spinal epidural MCL $[8,9]$. To the best of our knowledge, this is the first case report on primary spinal epidural indolent mantle cell lymphoma (IMCL) in a young male. This report describes the clinical features, imaging characteristics, histopathological features, immunophenotype, and clinical course of IMCL.

\section{Case Presentation}

A 20-year-old immunocompetent male arrived to our emergency department with a chief complaint of low back pain for six weeks followed by radicular pain and difficulty in bearing weight in both lower limbs for nine days. He also complained of decreased sensation over bilateral lower limbs and had normal bowel and bladder habits. He had a road traffic accident six weeks back while riding a motorcycle with minor injuries. There was no history of fever, headache, or night sweats.

On examination, no obvious spinal deformity was appreciated. Localized tenderness was present over the L3/L4 vertebra. Motor power varied across muscle groups: hip flexors (5/5 bilaterally), knee extensors ( $5 / 5$ bilaterally), ankle dorsiflexors ( $1 / 5$ on the right, $3 / 5$ on the left), long toe extensors ( $1 / 5$ on the right, $3 / 5$ on the left), and ankle plantar flexors (3/5 on the right, $4 / 5$ on the left). Sensations of both lower limbs were reduced from L4 downwards. Deep tendon reflexes of the knee and the ankle joints were absent. Plantar reflex was down-going bilaterally.

A provisional diagnosis of traumatic prolapsed intervertebral disc (with differentials of vertebral fracture, space-occupying lesion, and epidural abscess) was made, and an X-ray of the lumbosacral spine was performed, which showed loss of lumbar lordosis and no bony lesion. Magnetic resonance imaging (MRI) of the spine revealed posterior cortical erosion accompanied by epidural lesion, which was iso-intense on T1 


\section{Cureus}
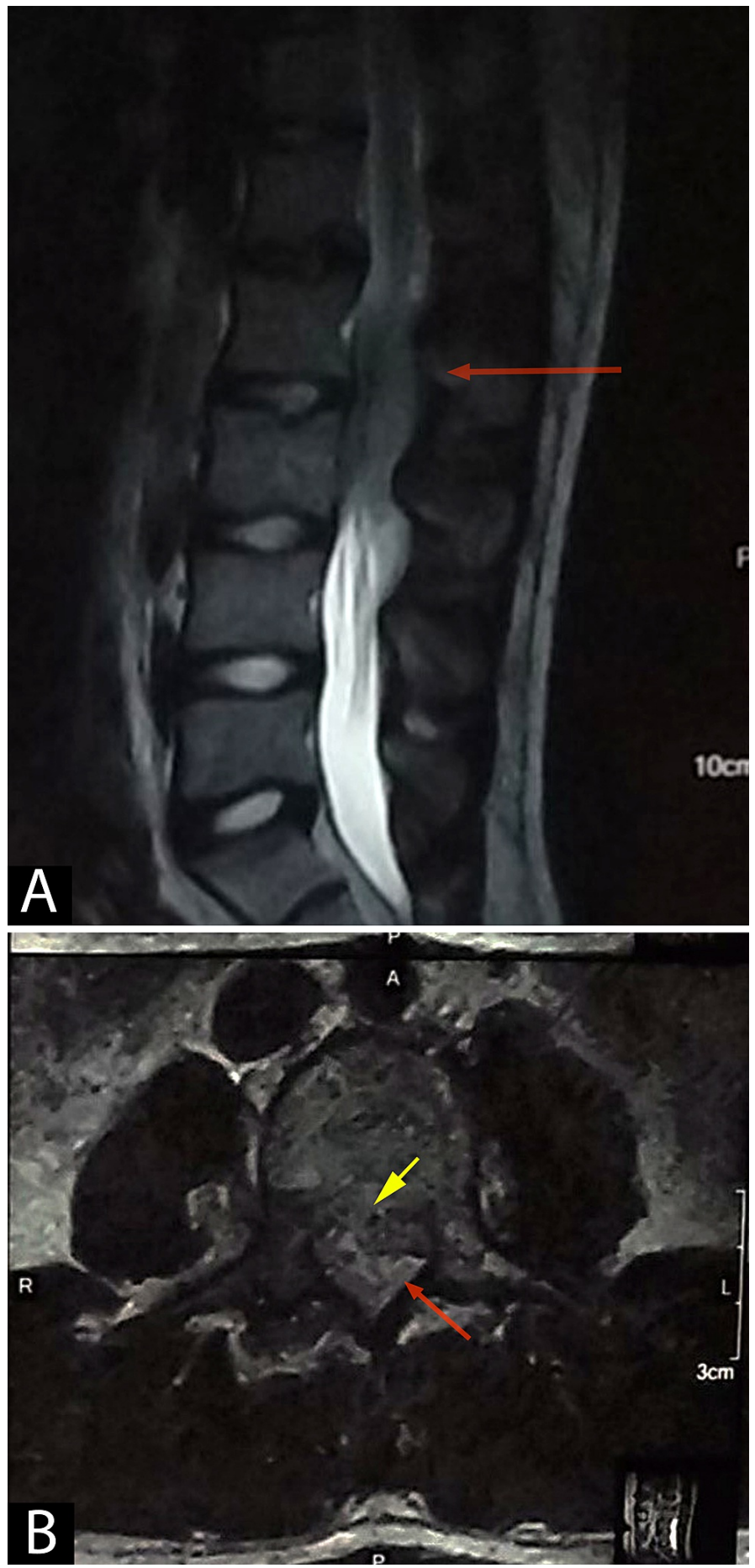

FIGURE 1: T2 sagittal (A) and axial (B) images showing a heterogeneous iso- to hyper-intense lesion extending from the L2 to L3 vertebral level, causing severe central spinal canal stenosis compressing the thecal sac (red arrows). A suspicious breach in the posterior cortex of the vertebral body is also noted (yellow arrow). Disc spaces between the L2 and L3 vertebral body appear intact. Prevertebral regions appear normal.

Gadolinium-enhanced MRI showed similar findings with a heterogeneously enhancing lesion extending from L2 to L3, suggestive of an extradural tumor over L2-L3 vertebrae (Figure 2). 


\section{Cureus}

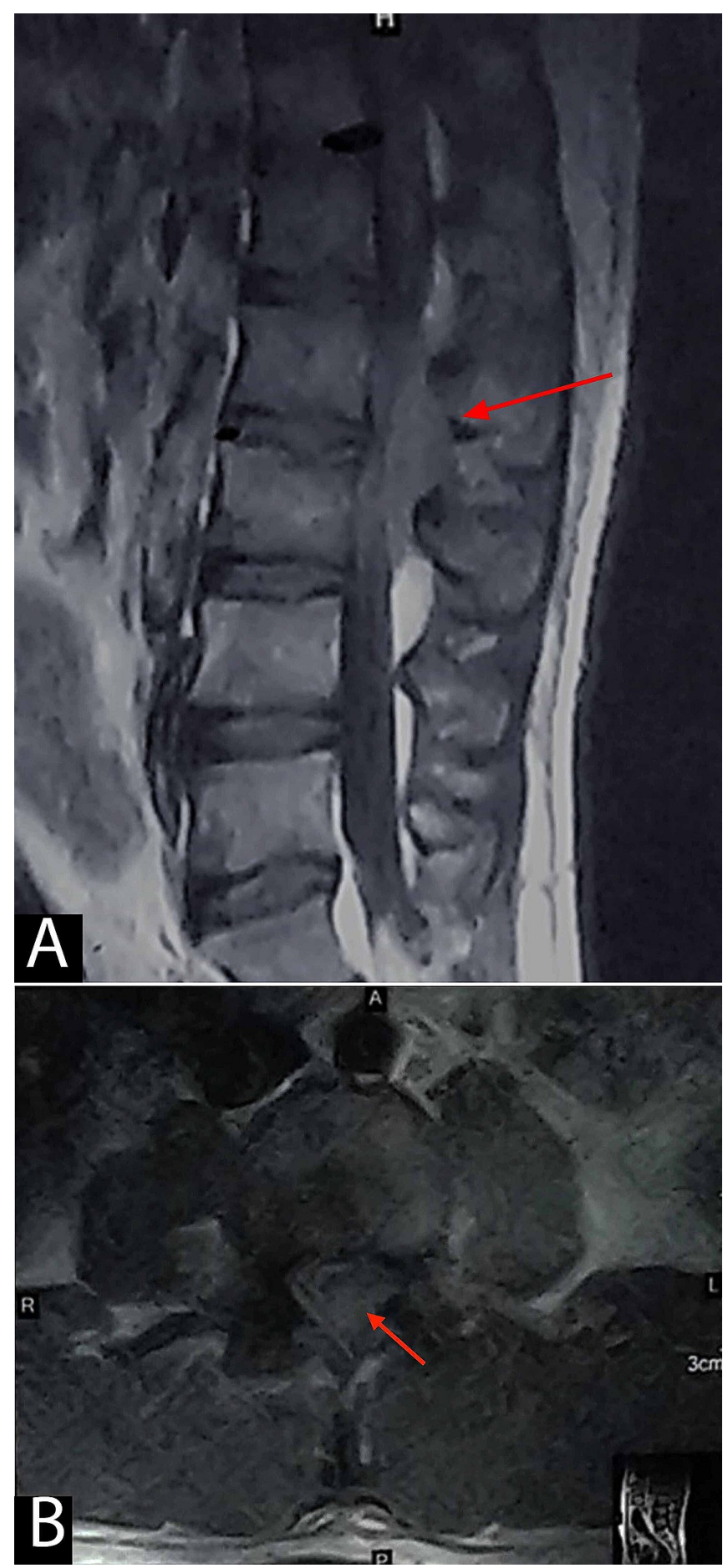

FIGURE 2: Post-contrast/gadolinium sagittal (A) and axial (B) images showing heterogeneous enhancement of the lesion (red arrows) predominantly occupying the posterior extradural region at the L2-L3 vertebral body levels and severely compressing the thecal sac.

However, no abnormal enhancement is seen within the vertebral bodies.

Chest X-ray, complete blood count (CBC), liver and renal function tests, peripheral blood smear, lactate dehydrogenase (LDH), uric acid, and urinalysis were normal. However, erythrocytic sedimentation rate (ESR) was $60 \mathrm{~mm} / \mathrm{hr}$ (normal range: 0-12 mm/hr) and CRP was $205.5 \mathrm{mg} / \mathrm{L}$ (normal range: 0-6 mg/L).

Decompression (laminectomy) and subtotal excision biopsy of the lesion were performed through the posterior midline approach. Intraoperative findings revealed a grey-colored, circumferential lesion that was soft to firm in consistency and was loosely adhered to the dura. A $4 \times 4 \mathrm{~cm}$ of the mass (in piecemeal) was 


\section{Cureus}

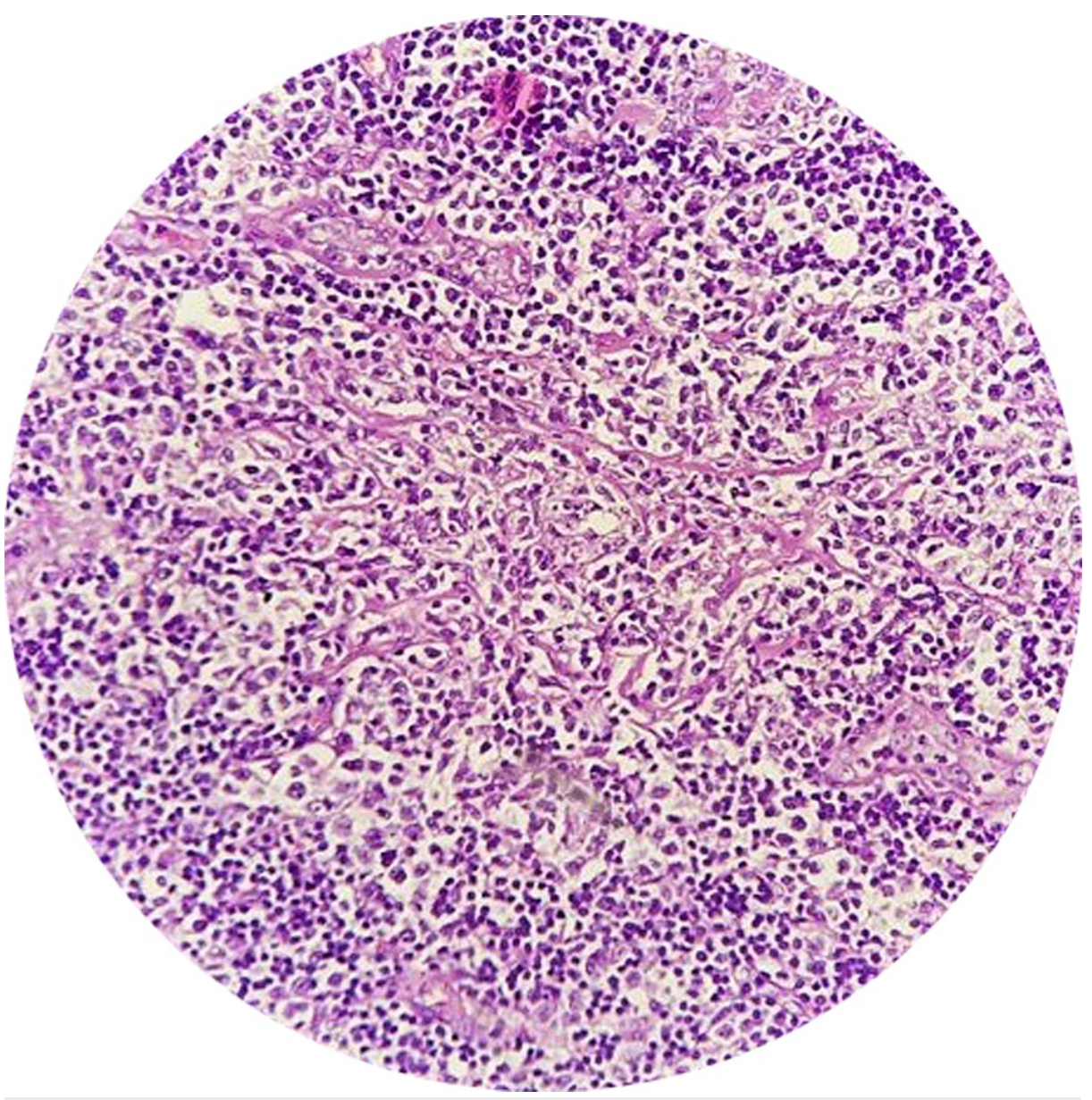

FIGURE 3: Histopathology (hematoxylin and eosin, x100) revealing diffuse proliferation of lymphoid cells, cleaved lymphocytes with prominent nucleoli, with few blast cells, increase in mitosis, and cells resembling Reed-Sternberg cells.

Immunohistochemistry reported it as $\mathrm{CD}^{+}, \mathrm{CD}^{+}, \mathrm{CD} 10^{-}, \mathrm{CD} 20^{+}, \mathrm{CD} 23^{+}, \mathrm{CD} 30^{-}, \mathrm{CD}_{9} 9^{+}, \mathrm{BCL}-2^{+}$, cyclin $\mathrm{D}^{+}$, Ki-67 ( $<10 \%$ positive), and PAX- $5^{+}$.

The postoperative period was uneventful. His radicular pain in both lower limbs improved immediately following surgery. No other lesion was identified on staging evaluation. Contrast-enhanced computed tomography scan (CECT) of the chest, abdomen, and pelvis excluded any accompanying abnormalities. Bone marrow aspiration and biopsy were negative for malignancy. His weakness improved gradually with physiotherapy to $5 / 5$ in all muscle groups in both lower limbs by the time of discharge. Postoperative MRI showed some residual mass at the L2-L3 level. He was comfortably walking when we referred him on the 22nd postoperative day to a cancer center for further treatment (chemotherapy and/or radiotherapy).

At three months follow-up, he was asymptomatic with complete neurological recovery. He is a migrant worker in India. On video-conferencing for a one-year follow-up, he was doing his routine job. He was under follow-up with an oncologist and planned for radiotherapy in a tertiary care center (New Delhi, India). The oncologist has followed the watch-and-wait policy as acceptable management since it was an indolent-type MCL.

\section{Discussion}

MCL is a variant of intermediate lymphocytic lymphoma, a distinctive type of NHL with unique clinical, pathological, and biological features [3]. It can affect the central nervous system either primarily or as a secondary spread. In histology, classical MCL may show a vaguely nodular, diffuse, or mantle zone growth pattern where the tumor cells surround preserved germinal centers as expanded mantle zones. The tumor cells are usually small- to medium-sized with irregular nuclear contours, resembling centrocytes. The 
immunophenotype of MCL is usually positive for CD5, CD19, and CD20, and negative for CD10 and BCL-6 [10]. Karyotyping can show chromosomal translocation $\mathrm{t}(11 ; 14)(\mathrm{q} 13 ; \mathrm{q} 32)$ as a genetic characteristic of MCL, which leads to the aberrant overexpression of cyclin D1, considered to be the hallmark of MCL [11].

Primary spinal epidural lymphoma is rare and accounts for $0.1 \%-6.5 \%$ of all lymphomas and $9 \%$ of all spinal epidural tumors [12]. Mantle cell tumors account for $5 \%$ of all NHLs [10]. Men are more affected than women (2:1). The median age is 60 years. MCL is typically diagnosed in patients at an advanced stage of the disease (Ann Arbor stage III/IV). Patient's presentation would be generalized lymphadenopathy with involvement of the spleen, liver, and bone marrow. Mostly MCL is nodal in origin; the extra-nodal form is rare. The most frequently involved extra-nodal sites are the gastrointestinal tract, Waldeyer's ring, and nasopharynx [13].

Aggressiveness of MCL is determined by over- or under-expression of many genes such as TP53 and SOXII [11], which can help in management planning. According to MIPI, there are three distinct groups. If incorporated with Ki67, the validity of MIPI will be more [7]. Ki67 is a protein expressed during cell replication and its level corresponds with aggressiveness of the tumor. Determann et al. using cut-off values of Ki67 positivity as <10\%, 10-30\%, and $>30 \%$ demonstrated three-year overall survival (OS) of $93 \%, 74 \%$, and $66 \%$, respectively [14].

In the past years, MCL had a poor prognosis, with a five-year OS rate of only $27 \%$. However, introduction of novel drugs and therapeutic options have shown significant improvements in treatment outcome, with a current five-year survival rate of 50\%-75\% [15].

Clinicians treating MCL have recognized a subset of patients with MCL who have a slow (indolent) disease course with significantly longer survival (>7-10 years). Indolent lymphoma is a slow-growing tumor compared to other aggressive lymphomas. Indolent lymphomas are less dangerous if left untreated; however, they are more difficult to cure because the lower proliferation of cells makes it less susceptible to chemotherapy. For indolent lymphomas, where cure is not an option, the most important treatment may be to avoid overtreatment, primum non nocere (above all else do no harm). Nonetheless, nonaggressive, indolent lymphomas can transform over time into aggressive lymphomas [16,17].

Our case presented with typical symptoms [12] of back pain for six weeks followed by bilateral lower limb radicular pain and neurological deficits for nine days with intact bowel and bladder habits and absence of $B$ symptoms (fever, night sweats, and weight loss). Laminectomy and subtotal excisional biopsy were performed as recommended [12]. Positive staining of PAX-5 and CD20, expression of cyclin D1, and less expression of Ki-67 suggest B-cell NHL, MCL type, and indolent course of the disease, respectively.

Unlike Schwechheimer et al.'s and Barnard et al.'s reported cases of spinal epidural MCL, in which the patients were over 70 years of age and had other co-morbidities, our patient was a young, healthy adult with no co-morbidity [8,9]. Both the cases reported by Schwechheimer et al. had lesions in the mid-thoracic region and were treated with surgery alone, and had poor outcomes because of other complications [8]. In the second reported case, the lesion was in the lumbosacral region for which laminectomy and partial resection of the tumor were performed followed by local radiotherapy but developed recurrence in cheek and mediastinum after seven months of treatment, which was further treated with chemotherapy [9]. These reports suggest that all the cases had an aggressive course of the disease. However, a case with bony MCL of thoracic (T10) and lumbar (L1) vertebrae was treated by kyphoplasty and biopsy, followed by eight cycles of combination chemotherapy, and remained in good clinical condition at one-year follow-up except complaining of slight back pain [18].

Our case had an excellent neurological improvement in the lower limbs immediately after the surgery. At three months' follow-up, he had full neurological recovery. The patient was asymptomatic and has resumed his job in India. Since it was an indolent type of MCL, the oncologist has followed the watch-and-wait policy. It is an acceptable management strategy in selected clinically well patients. The treatment was deferred since the time to treatment did not predict OS, and the median OS of the observation group was statistically longer than that of the early treatment group [16].

We agree with Tsukada et al. that functional recovery of spinal cord compression due to primary spinal epidural lymphoma is relatively better than metastatic carcinoma [19], and early diagnosis and surgery improve functional outcomes [20]. Indolent course of the disease and complete post-treatment neurologic improvement are the most significant favorable prognostic indicators of OS.

\section{Conclusions}

Primary spinal epidural IMCL is an extremely rare tumor due to which its diagnosis is challenging. A high degree of suspicion along with a team approach (spine surgeons, radiotherapists, oncologists, and pathologists) is vital for its diagnosis and management. The young age of the patient without co-morbidity, early diagnosis, and treatment are the keys to a favorable outcome.

\section{Additional Information}




\section{Disclosures}

Human subjects: Consent was obtained or waived by all participants in this study. Conflicts of interest: In compliance with the ICMJE uniform disclosure form, all authors declare the following: Payment/services info: All authors have declared that no financial support was received from any organization for the submitted work. Financial relationships: All authors have declared that they have no financial relationships at present or within the previous three years with any organizations that might have an interest in the submitted work. Other relationships: All authors have declared that there are no other relationships or activities that could appear to have influenced the submitted work.

\section{References}

1. Abdullah BB, Nausheen N, Baksh NK, Keerthi ND: Non-Hodgkin's lymphoma and spinal cord compression: a diagnostic challenge. Ital J Med. 2015, 9:380-3. 10.4081/itjm.2015.573

2. Weisenburger DD, Kim H, Rappaport H: Mantle-zone lymphoma: a follicular variant of intermediate lymphocytic lymphoma. Cancer. 1982, 49:1429-38. 10.1002/1097-0142(19820401)49:7<1429::aidcncr2820490720>3.0.c0;2-5

3. Weisenburger DD, Armitage JO: Mantle cell lymphoma-an entity comes of age . Blood. 1996, 87:4483-94. 10.1182/blood.V87.11.4483.bloodjournal87114483

4. Leonard JP, Williams ME, Goy A, Grant S, Pfreundschuh M, Rosen ST, Sweetenham JW: Mantle cell lymphoma: biological insights and treatment advances. Clin Lymphoma Myeloma. 2009, 9:267-77. 10.3816/CLM.2009.n.055

5. Fernàndez V, Salamero $\mathrm{O}$, Espinet $\mathrm{B}$, et al.: Genomic and gene expression profiling defines indolent forms of mantle cell lymphoma. Cancer Res. 2010, 70:1408-18. 10.1158/0008-5472.CAN-09-3419

6. Eskelund CW, Dahl C, Hansen JW, et al.: TP53 mutations identify younger mantle cell lymphoma patients who do not benefit from intensive chemoimmunotherapy. Blood. 2017, 130:1903-10. 10.1182/blood-201704-779736

7. Hoster E, Rosenwald A, Berger F, et al.: Prognostic value of Ki-67 index, cytology, and growth pattern in mantle-cell lymphoma: results from randomized trials of the European Mantle Cell Lymphoma Network. J Clin Oncol. 2016, 34:1386-94. 10.1200/JCO.2015.63.8387

8. Schwechheimer K, Hashemian A, Ott G, Müller-Hermelink HK: Primary spinal epidural manifestation of malignant lymphoma. Histopathology. 1996, 29:265-9. 10.1111/j.1365-2559.1996.tb01401.x

9. Barnard M, Perez-Ordoñez B, Rowed DW, Ang LC: Primary spinal epidural mantle cell lymphoma: case report. Neurosurgery. 2000, 47:1239-41; discussion 1242. 10.1097/00006123-200011000-00046

10. Campo E, Swerdlow SH, Harris NL, Pileri S, Stein H, Jaffe ES: The 2008 WHO classification of lymphoid neoplasms and beyond: evolving concepts and practical applications. Blood. 2011, 117:5019-32. 10.1182/blood-2011-01-293050

11. Sander B, Quintanilla-Martinez L, Ott G, et al.: Mantle cell lymphoma--a spectrum from indolent to aggressive disease. Virchows Arch. 2016, 468:245-57. 10.1007/s00428-015-1840-6

12. Cugati G, Singh M, Pande A, Ramamurthi R, Balasubramanyam M, Sethi SK, Singh AK: Primary spinal epidural lymphomas. J Craniovertebr Junction Spine. 2011, 2:3-11. 10.4103/0974-8237.85307

13. Vose JM: Mantle cell lymphoma: 2017 update on diagnosis, risk-stratification, and clinical management . Am J Hematol. 2017, 92:806-13. 10.1002/ajh.24797

14. Determann O, Hoster E, Ott G, et al.: Ki-67 predicts outcome in advanced-stage mantle cell lymphoma patients treated with anti-CD20 immunochemotherapy: results from randomized trials of the European MCL Network and the German Low Grade Lymphoma Study Group. Blood. 2008, 111:2385-7. 10.1182/blood2007-10-117010

15. Doorduijn JK, Kluin-Nelemans HC: Management of mantle cell lymphoma in the elderly patient. Clin Interv Aging. 2013, 8:1229-36. 10.2147/CIA.S35082

16. Martin P, Chadburn A, Christos P, et al.: Outcome of deferred initial therapy in mantle-cell lymphoma . J Clin Oncol. 2009, 27:1209-13. 10.1200/JCO.2008.19.6121

17. Hsi ED, Martin P: Indolent mantle cell lymphoma. Leuk Lymphoma. 2014, 55:761-7. 10.3109/10428194.2013.815353

18. Yang P, Lin J, Liu H, Shen H, Yang HL: Primary bone mantle cell lymphomas with multiple vertebral compression fractures: a case report. Oncol Lett. 2017, 13:1288-92. 10.3892/ol.2017.5553

19. Tsukada T, Ohno T, Tsuji K, Kita K, Kobayashi T, Deguchi K, Shirakawa S: Primary epidural non-Hodgkin's lymphoma in clinical stage IEA presenting with paraplegia and showing complete recovery after combination therapy. Intern Med. 1992, 31:513-5. 10.2169/internalmedicine.31.513

20. Xiong L, Liao LM, Ding JW, Zhang ZL, Liu AW, Huang L: Clinicopathologic characteristics and prognostic factors for primary spinal epidural lymphoma: report on 36 Chinese patients and review of the literature. BMC Cancer. 2017, 17:131. 10.1186/s12885-017-3093-z 